\title{
PENERAPAN ART THERAPY UNTUK MENINGKATKAN SELF-ESTEEM REMAJA PEREMPUAN DI LEMBAGA BIMBINGAN BELAJAR $X$
}

\author{
Renny Magdalena ${ }^{1}$ dan Titi Prantini Natalia ${ }^{2}$ \\ ${ }^{1}$ Fakultas Psikologi, Universitas Tarumanagara Jakarta \\ Email: rennymagdalena93@gmail.com \\ ${ }^{2}$ Fakultas Psikologi, Universitas Tarumanagara Jakarta \\ Email: titinatalia.2015@gmail.com
}

\begin{abstract}
ABSTRAK
Pada masa remaja seseorang rentan mengalami penurunan self-esteem. Remaja yang lebih rentan mengalami penurunan self-esteem adalah remaja perempuan, hal ini disebabkan remaja perempuan cenderung kurang puas dengan body imagenya. Self-esteem yang kurang baik berkaitan dengan tingkat depresi yang tinggi. Oleh karena itu, art therapy diterapkan untuk meningkatkan self-esteem dari 5 remaja perempuan di lembaga bimbingan belajar X. Beberapa penelitian sebelumnya menunjukkan bahwa art therapy efektif untuk meningkatkan self-esteem, karena art therapy dapat membantu seseorang untuk mengeksplorasi perasaan, sehingga dapat membantu mereka mengungkapan perasaan dan emosi yang tidak dapat diungkapkan dengan kata-kata. Penelitian ini menggunakan mixed method one group pre-test post-test design dengan menggunakan alat ukur State Self-Esteem Scale, wawancara semi terstruktur, dan draw a person test yang dianalisa untuk mengetahui perbandingan hasil sebelum dan sesudah pemberian intervensi. Berdasarkan hasil observasi dan draw a person test menunjukkan adanya peningkatan selfesteem dari kelima partisipan, namun berdasarkan alat ukur State Self-Esteem Scale hanya empat partisipan yang menunjukkan peningkatan skor total. Berdasarkan hasil tersebut dapat disimpulkan bahwa art therapy cukup efektif untuk meningkatkan self-esteem dari lima remaja perempuan di lembaga bimbingan belajar X.
\end{abstract}

Kata kunci: Art therapy, self-esteem, remaja, remaja perempuan, lembaga bimbingan belajar

\section{PENDAHULUAN \\ Latar Belakang}

Self-esteem atau harga diri merupakan evaluasi yang dibuat oleh individu mengenai hal-hal yang berkaitan dengan dirinya, terutama mengenai sikap penerimaan atau penolakan dan menunjukkan tingkat di mana individu meyakini dirinya mampu, penting, dan berharga (Coopersmith dalam Elkins, 1979). Self-esteem merupakan kunci dari kesuksesan, kesenangan, keberhargaan, dan produktivitas, ketika seseorang tidak dapat menghargai dirinya sendiri, maka ia tidak bisa merasakan kebahagiaan (Elkins, 1979).

Self-esteem dalam diri seseorang dipengaruhi oleh dirinya sendiri dan oleh lingkungan sekitar, maka self-esteem dalam diri seseorang cenderung fluktuatif (Elkins, 1979). Fluktuasi self-esteem terutama terjadi pada masa remaja. Pada masa remaja seseorang rentan mengalami penurunan selfesteem. Akan tetapi, berdasarkan hasil penelitian remaja perempuan lebih rentan untuk memiliki self-esteem buruk dibandingkan remaja laki-laki (Robins, et al., 2002). Salah satu hal yang memicu penurunan self-esteem remaja perempuan adalah karena perubahan fisik. Perubahan fisik yang terjadi dalam diri remaja perempuan dapat membuatnya merasa tidak puas dengan keadaan tubuhnya, misalnya karena lemak tubuhnya bertambah (Gross, 1984 dalam Santrock, 2003). Ketidakpuasan terhadap body image ini dapat menjadi salah satu hal yang membuat self-esteem seseorang menjadi lebih buruk (Healey, 2008).

Faktor lain yang berpengaruh terhadap self-esteem remaja adalah kondisi sosial ekonomi (socioeconomic status) dan dukungan yang didapatkan dari orang tua (Bean, Bush, McKenry \& Wilson, 2003; Mruk, 2006; Twenge \& Campbell, 2002). Selain dukungan dari orang tua, 
lingkungan sekitar juga turut berpengaruh terhadap self-esteem seseorang. Lingkungan sekitar yang mempengaruhi self-esteem seseorang adalah significant others (orang-orang yang terpenting atau terdekat dengannya). Significant others yang paling berpengaruh terhadap self-esteem seseorang, khususnya remaja, yaitu orang tua, guru, dan teman (Galbo, 1984 dalam Grgin \& Dekovic, 1990).

Lembaga bimbingan belajar $\mathrm{X}$ yang berbasis sosial dan memiliki misi pelayanan kepada anakanak dengan status sosial ekonomi rendah, saat ini memiliki 47 peserta didik yang berada di kelas 6 SD. Dari ke-47 peserta didik yang berada di lembaga bimbingan belajar X, ditemukan bahwa lima diantaranya memiliki self-esteem yang kurang baik. Berdasarkan hasil anamnesa dari kelima partisipan diketahui bahwa teman-teman di sekolah mereka sering mengata-ngatai mereka dengan perkataan-perkataan yang cukup kasar, seperti mengejek pekerjaan orang tua mereka, mengatangatai mereka secara fisik, dan mengejek ketika mereka melakukan kesalahan saat berbicara di depan umum. Selain itu, teman-teman di sekolah mereka pun beberapa kali memusuhi mereka tanpa sebab yang jelas dan membujuk teman-teman sekelasnya untuk turut serta memusuhi partisipan. Tingkat sosial ekonomi yang rendah dan kurangnya penerimaan dari teman sebaya membuat para partisipan memiliki self-esteem yang rendah.

Berdasarkan hasil screening kepada siswa-siswa kelas 6 SD di lembaga bimbingan belajar X dengan menggunakan tes draw a person, ditemukan bahwa kelima partisipan merupakan remaja yang paling memiliki self-esteem kurang baik di antara siswa-siswa lainnya. Hal ini dilihat dari kecilnya ukuran gambar, ukuran kaki yang kecil, keragu-raguan dan rasa malu ketika diminta menggambar, serta banyaknya kegiatan menghapus. Demikian pula ketika diberikan alat ukur State Self-Esteem Scale, kelima subjek juga tidak mendapatkan skor yang tinggi. Saat dilakukan konfirmasi kepada guru-guru di lembaga bimbingan belajar X, diketahui bahwa ternyata kelima siswa tersebut memang sulit diminta untuk maju ke depan kelas, misalnya ketika diminta untuk memimpin doa, mereka cenderung menolak, sehingga perlu diminta berulang kali hingga akhirnya mereka mau memimpin doa. Ketika diminta mengerjakan latihan soal di papan tulispun mereka biasanya kurang percaya diri dan mengatakan bahwa mereka merasa jawaban yang mereka berikan salah. 2 dari 5 siswa tersebut juga cenderung pasif dalam pertemanan, kedua siswa tersebut biasanya lebih memilih untuk duduk di bagian belakang kelas dan jarang berinteraksi dengan teman-teman lainnya.

Rendahnya self-esteem dapat berdampak pada berbagai aspek kehidupan remaja, seperti prestasi akademik, keterampilan sosial, dan kemampuan untuk merespon pada tantangan hidup, serta kesehatan mental (Birndorf, Ryan \& Auinger, 2005; Mruk, 2006). Selain itu, self-esteem yang rendah juga berdampak pada masalah-masalah psikologis, seperti depresi (Aditomo \& Retnowati, 2004; Sowislo \& Orth, 2013; Orth \& Robins, 2013). Oleh karena itu, proses terapi dengan pendekatan art therapy akan dilakukan untuk meningkatkan self-esteem kelima remaja perempuan yang yang menjadi peserta didik di lembaga bimbingan belajar X. Menurut American Art Therapy Association (2013) salah satu cara untuk meningkatkan self-esteem seseorang adalah dengan menggunakan art therapy, karena art therapy membantu memfasilitasi klien untuk menggunakan media seni, proses kreatif, dan hasil dari karya seni untuk mengeksplorasi perasaan, konflik emosi, kesadaran diri, menata perilaku, meningkatkan kemampuan sosial, sehingga hal ini dapat meningkatkan self-esteem yang dimiliki seseorang dan dapat mengoptimalkan diri mereka ketika berperilaku di dalam lingkungan sehari-hari. Beberapa penelitian juga menunjukkan bahwa art therapy efektif digunakan untuk meningkatkan self-esteem (Roghanchi, et al, 2013; Mousavi, \& Sohrabi, 2014; Kopytin \& Lebedev, 2013). Art therapy cocok digunakan untuk mengatasi masalah-masalah pada orang yang mengalami konflik emosi dan kurang dapat mengeksplorasi 
perasaan, sehingga dapat membantu mereka mengungkapan perasaan dan emosi yang tidak dapat diungkapkan dengan kata-kata (Withrow, 2004). Penelitian-penelitian sebelumnya terkait efektivitas art therapy terutama untuk meningkatkan self-esteem lebih banyak dilakukan di luar negeri, oleh karena itu peneliti ingin melihat apakah hal ini juga berlaku pada konteks di Indonesia, terutama pada masyarakat dengan tingkat sosial ekonomi yang rendah.

\section{Rumusan Masalah}

Apakah art therapy dapat diterapkan untuk meningkatkan self-esteem remaja perempuan di lembaga bimbingan belajar X?

\section{Tujuan penelitian}

Tujuan penelitian ini untuk mengetahui apakah art therapy dapat diterapkan untuk meningkatkan self-esteem remaja perempuan di lembaga bimbingan belajar X.

\section{METODE PENELITIAN \\ Partisipan penelitian}

Lima remaja perempuan yang berpartisipasi dalam art therapy memiliki karakteristik sebagai berikut: (a) berada dalam tahapan usia remaja awal (11-13 tahun), (b) merupakan peserta didik di lembaga bimbingan belajar X (lembaga bimbingan belajar dengan misi sosial yang diperuntukkan bagi anak-anak yang memiliki tingkat ekonomi menengah bawah), (c) memperoleh skor yang lebih rendah dari 76 (skor =<76) pada alat ukur State Self-Esteem Scale.

\section{Desain penelitian}

Penelitian ini menggunakan mixed method one group pre-test post-test design yang dilakukan dengan menggunakan alat ukur State Self-Esteem Scale, wawancara semi terstruktur, dan draw a person test yang dianalisa untuk mengetahui perbandingan hasil sebelum dan sesudah pemberian intervensi.

\section{Instrumen penelitian}

Peralatan yang digunakan dalam penelitian ini meliputi lembar informed consent, alat ukur State Self-Esteem Scale yang dikembangkan oleh Heatherton dan Polivy (1991) yang memiliki angka reliabilitas sebesar antara 0,73-0,81 (Janita, David, Anne, \& Jean, 2008), draw a person test yang dikembangkan oleh Machover (1949), alat ukur Culture Fair Intelligence Test, lembar observasi, lembar wawancara, alat tulis. Alat-alat art therapy yang terdiri dari pensil warna, crayon, cat poster, kertas gambar A3, karton buffalo, manik-manik, kain flannel, dan kapas dakron.

\section{Pengukuran}

Dependent variable dari penelitian ini, yaitu self-esteem diukur dengan menggunakan alat ukur State Self-Esteem Scale dan draw a person test, serta wawancara semi-terstruktur. Alat ukur State Self-Esteem Scale ini terdiri dari 20 item pertanyaan yang dikelompokkan menjadi 3 domain selfesteem, yakni performance (misalnya 'Saya merasa yakin dengan kemampuan yang saya miliki'), sosial (misalnya 'Saya khawatir termasuk dalam kategori orang yang gagal') dan fisik (misalnya 'Saya merasa puas dengan penampilan tubuh saya saat ini'). 13 dari 20 item pernyataan merupakan item negatif (misalnya 'Saya merasa bahwa saya tidak berprestasi atau menunjukkan kinerja yang baik'). Setiap item pertanyaan memiliki 5 pilihan respons yang harus dipilih berdasarkan perasaan individu. Tes draw a person dilakukan untuk mengetahui aspek kepribadian partisipan terkait konsep diri yang dimilikinya serta cara mempersepsikan diri di lingkungan. Analisis gambar dilakukan berdasarkan beberapa prinsip interpretasi Machover (1949) dan Ogdon (1974). 


\section{Prosedur penelitian}

Peneliti pertama-tama melakukan screening ke 47 siswa kelas 6 SD di lembaga bimbingan belajar $\mathrm{X}$ dengan menggunakan draw a person test. Kemudian peneliti mendapatkan 5 orang siswa memiliki self-esteem yang kurang baik. Berdasarkan hasil anamnesa dengan kelima partisipan diketahui bahwa kelima partisipan memang memiliki self-esteem yang kurang baik. Hal ini disebabkan oleh berbagai faktor, seperti teman-teman yang suka mengejeknya, memusuhinya, dan mereka tidak memiliki teman. Setelah dikonfirmasi kepada guru-guru di lembaga bimbingan belajar, diketahui bahwa ternyata kelima partisipan memang menampilkan ciri-ciri dari self-esteem yang kurang baik. Setelah itu, peneliti memberikan alat ukur state self-esteem scale untuk mengetahui tingkat self-esteem dari kelima partisipan. Setelah selesai diberikan program intervensi, kemudian peneliti mengadministrasikan kembali alat ukur state self-esteem scale dan draw a person test sebagai post-test. Hasil pre-test dan post-test kemudian dibandingkan untuk mengetahui dampak dari program intervensi terhadap tingkat self-esteem dari kelima remaja.

\section{Pelaksanaan intervensi}

Intervensi art therapy yang dijalankan berjumlah 7 sesi. Durasi dari masing-masing sesi sekitar 70 hingga 90 menit. Tahapan-tahapan dari sesi tersebut dirancang berdasarkan pada 5 tahapan yang perlu dilakukan dalam art therapy yaitu (a) perkenalan dan warm-up, yaitu dengan membuat karya seni bebas, tahap ini juga dapat menjadi aktivitas untuk menyesuaikan diri satu sama lain dalam lingkungan dan orang-orang yang baru, saling mengenal lebih dalam satu sama lain. Dalam penelitian ini dilakukan dengan menggambar scribble dan mencari bentuk dari gambar scribble tersebut; (b) recalling event, mencoba membuka kembali ingatan tentang kejadian yang telah dialaminya, kemudian mengungkapkan perasaan terhadap kejadian tersebut. Dalam penelitian ini dilakukan dengan menggambar diri; (c) emotional expression and issues, mencoba mengungkapkan emosi-emosi yang selama ini terpendam dalam diri subyek, seperti kecemasan, ketakutan, kesedihan, dan kemarahan. Dalam penelitian ini dilakukan dengan menggambar pengalaman terburuk bersama orang lain dan perasaan saat kejadian tersebut terjadi; (d) restitution, menyadari permasalahan dan kenyataan yang terjadi, mencari jalan keluar untuk mengatasi permasalahan tersebut. Dalam penelitian ini dilakukan dengan menggambar cara mengatasi pengalaman terburuk, membuat surat cinta untuk diri sendiri, dan menggambar diri ideal di masa depan; (e) termination, penghentian terapi, dalam penelitian dilakukan dengan membuat gantungan kunci berbentuk inisial nama (Landgarten, 1981).

\section{HASIL DAN PEMBAHASAN \\ Evaluasi Draw-A-Person Test}

Secara umum, terdapat perubahan pada gambar figur orang yang dibuat oleh masing-masing partisipan antara pre-test dan post-test. Perbedaan itu dapat terlihat dari bertambah besarnya ukuran gambar, berkurangnya jumlah kegiatan menghapus, kualitas goresan yang semakin baik, ukuran leher menjadi lebih proporsional, dan detail dari gambar. Hal ini mengindikasi adanya peningkatan pada self-esteem dari kelima partisipan setelah mengikuti intervensi kelompok.

\section{Evaluasi State Self-Esteem Scale: Perbandingan Pre-Test \& Post-Test}

Total skor State Self-Esteem Scale (SSES) yang diperoleh keempat partisipan sebelum berpartisipasi dalam intervensi berbeda dengan total skor yang didapat setelah mengikuti 7 sesi intervensi. Total skor dari partisipan L, I, J dan D, mengalami peningkatan. Sedangkan satu orang partisipan lainnya tidak mengalami perubahan dalam skor SSES, partisipan ini adalah S. 
Tabel 1. Skor Total Alat Ukur State Self-Esteem Scale pada Pre-test dan Post-test

\begin{tabular}{cccc}
\hline & Pre-Test & \multicolumn{2}{c}{ Post-Test } \\
\hline Partisipan & Skor Total SSES & Partisipan & Skor Total SSES \\
\hline L & 55 & L & 65 \\
\hline I & 63 & I & 76 \\
\hline S & 69 & S & 69 \\
\hline J & 68 & J & 81 \\
\hline D & 53 & D & 58 \\
\hline
\end{tabular}

L mengalami peningkatan 10 poin skor total. Pada pre-test L mendapat skor 55 sedangkan pada post-test L memperoleh skor total 65 . Skor total I pada pre-test 63 , sedangkan pada post-test 76 , hal ini berarti I mengalami peningkatan skor total sebanyak 13 poin. Skor total S pada pre-test maupun post-test 69 , hal ini berarti $\mathrm{S}$ tidak mengalami perubahan skor total. J mengalami peningkatan skor total sebanyak 13 poin, pada pre-test J mendapatkan skor total 68 sedangkan pada post-test $\mathbf{J}$ mendapatkan skor total 81 . Skor total D pada pre-test yaitu 53, sedangkan pada post-test 58 . Hal ini berarti D mengalami peningkatan skor sebanyak 5 poin. Total skor dari kelima partisipan, pada pre-test lebih rendah dari 76 (skor < 76/100). Pada post-test tiga orang partisipan mendapatkan skor total kurang dari 76, seorang partisipan setara dengan 76, dan seorang partisipan lainnya lebih dari 76. Hal ini berarti ada dua orang partisipan yang memiliki self-esteem tinggi setelah mengikuti 7 sesi intervensi.

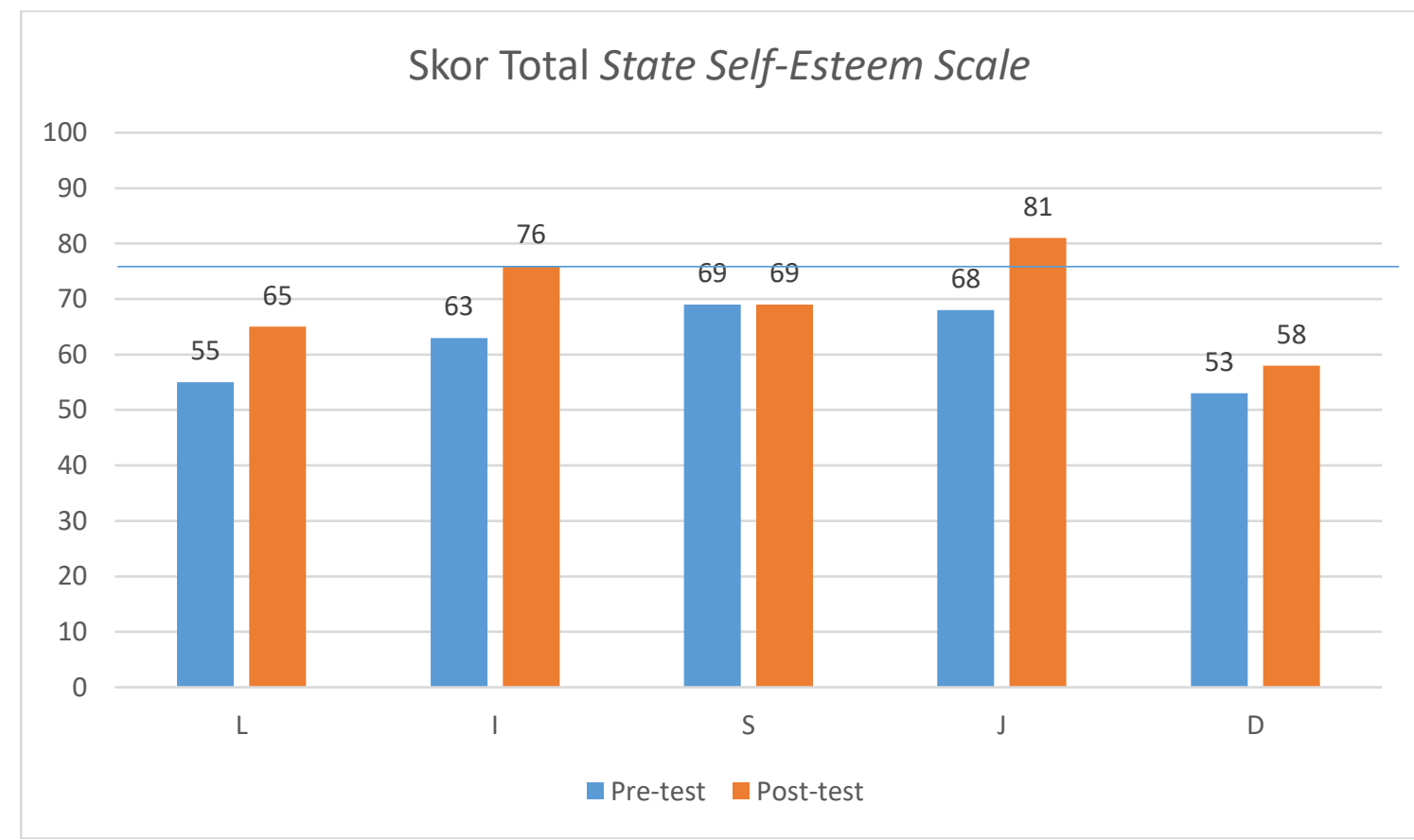

Gambar 1. Skor Total Alat Ukur State Self-Esteem Scale Pre-test dan Post-test

\section{KESIMPULAN, DISKUSI DAN SARAN}

Hasil observasi menunjukkan adanya peningkatan inisiatif dari seluruh partisipan, terutama dalam hal mengungkapkan pendapat dan dari cara mereka mengevaluasi diri mereka menjadi lebih positif, serta tidak lagi mempermasalahkan kekurangan dari dirinya. Berdasarkan hasil post-test dari draw a person test, juga mengindikasikan adanya peningkatan self-esteem dari kelima partisipan. Berdasarkan hasil dari alat ukur State Self-Esteem Scale (SSES) terdapat peningkatan skor total dari keempat partisipan, sedangkan satu orang partisipan lainnya tidak mengalami 
perubahan skor total. Terdapat perbedaan skor yang cukup berarti pada partisipan yang mengalami peningkatan skor pada alat ukur SSES. Oleh karena itu, dapat disimpulkan bahwa Art Therapy cukup efektif untuk meningkatkan self-esteem lima remaja perempuan di lembaga bimbingan belajar X.

Faktor-faktor yang mempengaruhi hasil intervensi adalah kelima partisipan menyukai kegiatan membuat karya seni, sehingga mereka tertarik dengan jenis aktivitas yang dilakukan selama intervensi. Hal ini membuat atensi dan kualitas keiikutsertaan partisipan dalam mengikuti sesi pun menjadi lebih baik. Di samping itu, adanya buku jurnal intervensi juga membuat mereka dapat menuliskan dan mengingat kembali perasaan dan pengalaman mereka selama intervensi, kohesivitas antar anggota kelompok juga dapat membuat mereka menjadi semakin nyaman dalam menjalankan program intervensi.

Selain dari segi internal, ada pula faktor eksternal yang mempengaruhi hasil dari intervensi yakni kondisi atau setting lokasi di mana kegiatan dilaksanakan yang tidak banyak gangguan dari orang lain. Jenis intervensi yang menghadirkan 4 partisipan lain juga mempengaruhi hasil evaluasi intervensi karena memberikan kesempatan pada tiap individu untuk belajar dari pengalaman orang lain serta saling memberikan umpan balik positif satu sama lain (Brabender, Fallon \& Smolar, 2004; Johnson, 2017). Terakhir, karateristik dari kedua alat ukur yang digunakan yakni draw a person test dan State Self-Esteem Scale, juga memiliki pengaruh terhadap hasil pengukuran selfesteem yang dilakukan sebelum dan setelah intervensi dilaksanakan.

\section{Saran}

Beberapa saran yang dapat diberikan kepada kelima partisipan antara lain: (a) Partisipan sebaiknya menjalankan saran-saran yang diberikan fasilitator seperti menempel atau meletakan surat cinta yang mereka buat untuk diri mereka sendiri di tempat yang mudah dilihat, sehingga mereka dapat melihatnya dan memotivasi diri mereka, mengingat saat mereka membuat dan membaca surat cinta itu mereka mengatakan bahwa mereka merasa lebih berharga; (b) Partisipan juga dapat melihat-lihat kembali jurnal intervensi agar mereka dapat mengingat konten dari program intervensi seperti cara mengatasi kejadian terburuk saat berhadapan dengan orang lain, cara mencapai diri ideal mereka, dan mengingat bahwa mereka pernah bisa menghasilkan karya yang berharga; (c) Partisipan juga sebaiknya menjalankan langkah-langkah konkrit yang telah mereka buat dan mereka diskusikan pada sesi keenam untuk mendapai diri ideal menurut mereka sendiri. Ketika mereka berhasil menjalankan langkah-langkah konkrit yang mereka buat tersebut, mereka dapat memberikan apresiasi untuk diri mereka sendiri, misalnya dengan melakukan hal-hal yang mereka sukai saat mereka bisa menjalankan langkah-langkah konkrit yang telah direncanakan pada sesi keenam. Hal ini sesuai dengan prinsip operant conditioning yang dicetuskan oleh Skinner (dalam Feist \& Feist, 2009) bahwa reinforcement dapat menguatkan perilaku dan membuat kemungkinan berulangnya menjadi semakin kuat; (d) Partisipan juga dapat memberikan apresiasi kepada diri mereka sendiri setiap kali mereka berhasil melakukan suatu hal, misalnya ketika mendapatkan nilai yang baik, mampu mengungkapkan pendapat, dan hal-hal lainnya agar mereka dapat lebih menghargai diri mereka sendiri dengan menuliskan kata-kata pujian untuk diri mereka sendiri di buku diary. Hal ini sesuai dengan yang dicetuskan oleh Coopersmith (dalam Elkins, 1979) bahwa self-esteem merupakan evaluasi yang dibuat oleh seseorang mengenai dirinya, ketika orang tersebut dapat memberikan evaluasi positif mengenai dirinya, maka selfesteemnya pun akan meningkat; (e) Diskusi dengan individu lain, misalnya dengan anggota kelompok, juga disarankan untuk dilakukan agar mereka bisa mendapatkan masukan positif dan teman-teman lainnya juga dapat memotivasi mereka dan memberikan mereka pujian. Hal ini sesuai dengan prinsip maintenance dalam teknik modifikasi perilaku. Adanya peer facilitator 
dapat membuat perilaku itu tetap bertahan dalam diri partisipan tersebut (Kazdin, 2013).

\section{Saran untuk penelitian selanjutnya}

Beberapa saran yang dapat dipertimbangkan untuk penelitian selanjutnya yaitu: (a) Mempertimbangkan tempat dilaksanakannya program intervensi dan membuatnya menjadi lebih kondusif; (b) Sebaiknya juga memperhatikan minat para partisipan terhadap kegiatan membuat karya seni dan kohesivitas dari kelompok tersebut; (c) Menambah jumlah sesi sehingga program intervensi dapat menjadi lebih optimal (Withrow, 2004); (d) Jenis-jenis karya yang dihasilkan dari program intervensi dapat diarahkan pada karya-karya yang memiliki nilai guna dalam kehidupan sehari-hari, misalnya seperti membuat gelang, gantungan kunci, desain pada kaos, dan lain sebagainya.

\section{Ucapan Terima Kasih}

Ucapan terima kasih kepada partisipan yang telah bersedia untuk diwawancarai dan bersedia menjalankan program intervensi ini dengan kooperatif. Peneliti juga mengucapkan terima kasih kepada lembaga bimbingan belajar X yang bersedia bekerja sama dengan peneliti.

\section{REFRENSI}

Aditomo, A., \& Retnowati, S. (2004). Perfeksionisme, harga diri, dan kecenderungan depresi pada remaja akhir. Jurnal Psikologi Universitas Gadjah Mada, 1, 1-14.

American Art Therapy Association. (2013). What is art therapy?. Diakses pada 13 November 2016, dari http://www.arttherapy.org/upload/whatisarttherapy.pdf.

Bean, R. A., Bush, K. R., McKenry, P. C., \& Wilson, S. P. (2003). The impact of parental support, behavioral control, and psychological control on the academic achievement and self-esteem of African American and European American adolescents. Journal of Adolescent Research, 18(5), 523-541.

Birndorf, S., Ryan, S., \& Auinger, P. (2005). High self-esteem among adolescents: Longitudinal trends, sex differences, and protective factors. Journal of Adolescent Health, 37, 194-201.

Elkins, D. P. (1979). Self concept sourcebook ideas and activities for building self-esteem. Rochester, NY: Growth Associates.

Feist, G., \& Feist, J. (2009). Theories of Personality. New York, NY: McGraw Hill.

Grgin, K. L., \& Dekovic, M. (1990). The contribution of significant others to adolescents' selfesteem. Journal Adolescence, 100(25), 839-846.

Healey, J. (2008). Body image and self-esteem. Thirroul, NSW: Spinney Press.

Heatherton, T. F., \& Polivy, J. (1991). Development and validation of a scale for measuring state self-esteem. Journal of Personality and Social Psychology, 60(6), 895-910.

Kazdin, A. (2013). Behavior modification in applied settings (5th Ed.). Illanois: Waveland Press, Inc.

Kopytin, A., \& Lebedev, A. (2013). Humor, self-attitude, emotions, and cognitions in group art therapy with war veterans. Art Therapy, 30(1), 20-29.

Landgarten, H.B. (1981). Clinical art therapy a comprehensive guide. New York, NY: Bruner/Mazel publishers.

Machover, K. (1949). Personality projection in the drawing of the human figure: A method of pesonality investigation. Springfield, Il: Charles C. Thomas.

Mousavi, M., \& Sohrabi, N. (2014). Effects of art therapy on anger and self-esteem in aggressive children. Procedia-Social and Behavioral Sciences, 113, 111-117.

Mruk, C. J. (2006). Self-esteem research, theory and practice: Toward a positive psychology of 
self-esteem ( $3^{r d}$ ed.). New York, NY: Springer Publishing Company.

Ogdon, D. (1974). Psychodiagnostics and personality assessment: A handbook (2 ${ }^{\text {nd }} E d$.). Los Angeles,LA: Western Psychological Services.

Orth, U., \& Robins, R. W. (2013). Understanding the link between low self-esteem and depression. Current Directions in Psychological Science, 22(6), 455-460.

Robins, R.W., Trzeniewski, K.H., Tracey, J.L., Potter, J., Gosling, S.D. (2002). Age differences in self-esteem from age 9 to 90. Psychology and Aging, 17, 423-434.

Roghanchi, M., Mohamad, A. R., Mey, S. C., Momeni, K. M., \& Golmohamadian, M. (2013). The effect of integrating rational emotive behavior therapy and art therapy on self-esteem and resilience. The Arts in Psychotherapy, 40(2), 179-184.

Santrock, J.W. (2003). Adolescence ( $\left.6^{\text {th }} e d\right)$. New York : McGraw-Hill.

Sowislo, J. F., \& Orth, U. (2013). Does low self-esteem predict depression and anxiety? A metaanalysis of longitudinal studies. Psychological bulletin, 139(1), 213.

Twenge, J. M., \& Campbell, W. K. (2002). Self-esteem and socioeconomic status: A metaanalytic review. Personality and Social Psychology Review, 6(1), 59-71.

Withrow, R.L. (2004). The use of color in art therapy. Journal of Humanistic Counseling, Education and Development, 43 (1): Spring 2014. 